\title{
19 DAFTAR SARAN TERBAIK UNTUK ADMINISTRASI SEKOLAH
}

\author{
Anis Fujiati \\ Universitas Nahdlatul Ulama Sidoarjo
}

\section{Pengantar}

Berikut adalah beberapa tips bertahan hidup untuk kepala sekolah atau pemilik sekolah atau wirausahawan sekolah, baik Anda yang baru dalam administrasi sekolah, berjuang untuk tetap berada di atas air, atau hanya ingin menyegarkan kembali praktik terbaik Anda. Kami telah menulis beberapa tips tentang Kepemimpinan Pendidikan dan Praktik Terbaik untuk Kepala Sekolah dan wirausaha pendidikan. Kami membagikan beberapa tips terbaik untuk administrator, wirausahawan pendidikan dan kepala sekolah yang efektif.

\section{Ada Apa dengan Pendidikan}

Pendidikan itu sebuah perhiasan dalam kemakmuran dan tempat bernaung dalam kesengsaraan (Maula, Mufidah, Rosyidah, \& Purnomo, 2017). Guru merupakan seorang yag memilki tugas mulia sebagai pendidik dan pengajar sekaligus sebagai pembentuk kepribadian siswa 
(Maula et al., 2018). Cari ilmu yang bermanfaat dan patuhi aturan-aturan yang ada. Bijaksana dan pantang menyerah dalam belajar adalah kunci kesuksesan. Pendidikan adalah pelajaran yang harus kita pelajari setiap hari baik dari buku, lingkungan, teman, maupun keluarga agar kita tidak tertinggal (Qori'ah, Sholichah, Purnomo, \& Rosyidah, 2017). Hasil penelitian menunjukkan bahwa penerapan pembelajaran dapat meningkatkan prestasi siswa; dan tes menunjukkan bahwa prestasi belajar siswa kelas belajar lebih baik daripada siswa kelas konvensional (Iskandar, Rizal, Kurniasih, Sutiksno, \& Purnomo, 2018). Tidak diragukan lagi berikut ini beberapa tips untuk para pemimpin sekolah.

\section{Jadilah Linchpin}

Pemimpin sekolah sebisanya tegas, toleran terhadap bawahannya dan mengayomi. Pendidikan adalah catatan masa lalu dan pengajaran masa kini untuk masa depan bangsa. Pendidikan adalah menyampaikan ilmu dan mentransformasi orang lain menjadi lebih baik (Fidiana, Istiana, Rosyidah, \& Purnomo, 2017). Seth Godin adalah seseorang yang perlu Anda ketahui jika Anda belum melakukannya karena ia memiliki cara penulisan yang sederhana saat mengomunikasikan ide-ide yang berani dan cemerlang. Tagline bukunya, Linchpin, 
mengkomunikasikan ide dengan sempurna - Apakah Anda sangat diperlukan? (Bauer, 2019).

\section{Fokus}

Pendidikan Indonesia membutuhkan peningkatan akses, mutu dan relevansi pendidikan untuk memberi manfaat membangun bagi pendidikan dan rakyat Indonesia (Irawan et al., 2018). Pastikan Anda fokus pada apa yang penting daripada apa yang mendesak setiap hari. Teliti rencana strategis sekolah dan fokus pada apa yang perlu dicapai untuk meningkatkan pembelajaran siswa termasuk keterlibatan siswa, motivasi siswa dan kesejahteraan siswa (Driscoll, 2018).

\section{Beristirahat}

Sangat mudah bagi saya untuk terlibat dalam proyek jika saya mengalami aliran atau tugas-tugas yang tidak penting seperti email jika saya tidak menganggarkan waktu dengan bijak. Dengan sering istirahat, saya tetap segar, FOKUS, dan membuang semua energi saya pada proyek yang tepat di depan saya. Tekan tombol jeda. Anda akan lebih produktif dalam jangka panjang (Bauer, 2019). Tips kelola sekolah adalah senantiasa belajar dan bekerja keras. Bersabarlah dengan masalah, sesungguhnya didalam kesulitan ada kemudahan (Sholichah, Istiqomah, Rosyidah, \& Purnomo, 2017). 


\section{Syarat Pemimpin Pendidikan yang Baik}

(Peel District School Board, 2019) Anda mungkin sudah memiliki banyak sifat yang dimiliki para pemimpin. Siapa pun bisa menjadi pemimpin jika mereka:

- memiliki keinginan kuat untuk mengambil tindakan dan mencoba hal-hal baru

- merangkul pembelajaran seumur hidup dan tidak pernah percaya mereka memiliki semua jawaban

- usulkan kegiatan positif

- mengambil tanggung jawab

- mengekspresikan diri mereka secara efektif

- berpikir cepat dan tetap tenang di bawah tekanan

- tunjukkan kasih sayang dan empati setiap saat

- membuat kontak pribadi di setiap kesempatan

- gunakan imajinasi mereka

- lakukan penilaian yang baik

- dengarkan yang lain

- dapat memotivasi orang lain

- menetapkan prioritas - mengutamakan hal pertama

- mencari cara-cara kreatif untuk bertemu orang di tengah jalan .

\section{Gunakan Bantuan Perekrutan}

Salah satu pekerjaan terbesar administrator sekolah di mana-mana adalah menemukan orang yang tepat untuk bekerja di sekolah mereka. Kepribadian, 
karakter, pendidikan, izin dan rujukan keamanan semuanya berperan dalam merekrut guru pengganti terbaik, perawat, asisten guru, dan personel pendukung (Kerns, 2016).

\section{Rangkullah Ide-Ide Baru}

Guru merupakan seorang pendidik dan pengajar sekaligus sebagai pembentuk kepribadian siswa yang unggul, berwawasan dan baik (Maula et al., 2018). Jika Anda atau salah satu guru Anda menemukan sesuatu yang baru, libatkan semua orang dengan belajar dan mengeksplorasi bersama (Drewitt, 2017).

\section{Bekerja dengan Orang}

Sebagai kepala sekolah, Anda harus belajar bekerja dengan semua tipe orang yang berbeda. Setiap orang memiliki kepribadian mereka sendiri, dan Anda harus belajar bekerja secara efektif dengan masingmasing tipe. Kepala sekolah terbaik mampu membaca orang dengan baik, mencari tahu apa yang memotivasi mereka, dan secara strategis menanam benih yang pada akhirnya akan berkembang menjadi kesuksesan. Kepala sekolah harus bekerja dengan setiap pemangku kepentingan di masyarakat. Mereka harus menjadi pendengar yang terampil yang menghargai umpan balik dan menggunakannya untuk membuat perubahan yang dapat dikenali. Kepala sekolah harus berada di 
garis depan, bekerja dengan pemangku kepentingan untuk meningkatkan komunitas dan sekolah mereka (Meador, 2019).

\section{Selalu Ingat Bahwa Komunikasi Adalah Kunci}

Pengamatan dengan umpan balik formatif sangat membantu guru Anda memenuhi harapan Anda (Drewitt, 2017). Siswa perlu memahami apa yang diketahui dan apa yang diminta untuk memiliki kemampuan menjawab (Suci et al., 2018). kesabaran dan komunikasi yang baik dengan masyarakat sekitar adalah kunci untuk dapat mengatasi masalah dan bisa bangkit dari keterpurukan manajemen pendidikan. Prinsip utama dan kepemimpinan wirausaha pendidikan adalah disiplin, kreatif, cerdas dan ulet (Qori'ah et al., 2017).

\section{Sikap adalah Kunci}

Peka terhadap bagaimana perasaan siswa Anda tentang diskusi publik tentang masalah disorganisasinya. Para guru, staf pendukung, atau spesialis luar tidak boleh secara terbuka memanggil seorang siswa untuk organisasi, manajemen bahan atau manajemen waktu, dan bahkan lebih penting lagi bahwa kehidupan rumah tangganya bebas dari penghinaan. Libatkan siswa Anda dalam percakapan tentang bidang-bidang kehidupan di mana disorganisasi menghalangi pencapaian tujuan, dan 
mengapa organisasi itu penting. Buat pernyataan positif tentang siswa Anda di depan umum, dan bagikan perbaikan yang diamati dengan siswa Anda juga (Springer, 2019).

\section{Pengamatan Guru}

Melakukan tiga atau empat pengamatan dalam satu hari membantu saya melihat berbagai pelajaran di semua tingkatan kelas. "Hari" berdedikasi ini memastikan bahwa saya berada di gedung menikmati pembelajaran dengan siswa dan guru. Saya mencurahkan waktu dengan guru selama blok perencanaan mereka yang segera mengikuti pengamatan kelas. Pendekatan ini memberikan umpan balik langsung dan memastikan proses yang tepat waktu (Communicator, 2017).

\section{Never Stop Learning}

Para pemimpin hendaknya menghadiri konferensi yang paling mungkin meningkatkan keterampilan dan pengetahuan mereka. Itu mungkin berarti meninggalkan konferensi tradisional dan mencari yang baru. Para pemimpin harus menerapkan logika yang sama kepada para guru. Artikel "Memotivasi Guru dengan Menjadi Pemimpin yang Lebih Efektif" menekankan pentingnya pertumbuhan karyawan dan terbuka terhadap ide-ide baru. "Anda 
ingin karyawan Anda terus belajar dan tumbuh," kata artikel itu (Watanabe-Crockett, 2018).

\section{Tingkatkan Email Anda}

Cara memimpin sekolah adalah senantiasa musyawarah serta sharing bersama (Yuniarti, Kautsari, Sholichah, Purnomo, \& Rosyidah, 2017). Kotak Masuk dan Polymail Google adalah dua opsi yang memiliki fitur "bumerang" atau "kirim nanti". Opsi ini memungkinkan Anda untuk membalas semua email Anda, mengirim yang baru, dan membersihkan kotak masuk Anda setiap saat, siang atau malam, tetapi email tidak akan tiba di kotak masuk penerima sampai waktu yang Anda pilih. Jika Anda bertanya-tanya mengapa ini adalah penghemat produktivitas, pikirkan kapan terakhir kali Anda mengirim email tepat sebelum jam tidur yang berubah menjadi percakapan, atau anggota staf khawatir Anda mengharapkan balasan untuk email yang dikirim pada pukul 10:30 malam (Communicator, 2017).

\section{Menggunakan Alat Digital Gratis}

Manajemen sekolah dilakukan dengan menerapkan standar kualitas dalam rekrutmen pengajar yaitu kedekatannya dengan amaliyah (Munjidah, Zannah, Purnomo, \& Rosyidah, 2017). Jika Anda ingin mendapatkan semua guru bersemangat ketika datang untuk menggunakan teknologi dan media di kelas Anda, Anda harus terlebih dahulu 
menunjukkan kepada mereka alat yang bisa mereka mainkan. Anda dapat mulai dengan alat digital gratis dalam contoh ini. Saat ini, ada banyak alat pendidikan yang tersedia di sekitar Anda yang memungkinkan Anda untuk melakukan apa yang Anda inginkan (Fedena, 2018).

\section{Perencanaan dan Pelaporan: Piagam Sekolah}

Pemimpin sekolah dan wirausaha pendidikan seharusnya senantiasa menikmati proses karena tidak ada hal yang besar yang tidak dilakukan dari hal yang kecil. Semua butuh proses, karena kesuksesan tidak datang secara langsung tanpa berproses (Maula et al., 2017). Panduan ini berisi informasi tentang pengembangan, peninjauan, dan pembaruan piagam (Educational Leaders, 2019).

\section{Bergerak di Sekitar Kelas}

Sebagian besar guru berdiri di depan ruangan tanpa memindahkan posisi mereka. Merupakan ide bagus untuk berjalan-jalan saat Anda mengajar. Ini bukan hanya pendekatan pengajaran yang berbeda, tetapi juga membantu mengawasi apa yang dilakukan siswa (Edsys, 2016).

\section{Manajemen Wirausaha}

Toleransi, bekerja sama, bertanggungjawab, dan amanah adalah prinsip wirausaha pendidikan 
(Nahdiyah, Amrina, Purnomo, \& Rosyidah, 2017). Edupreneur atau educational entrepreneur berasal dari dua kata yaitu education bermakna pendidikan dan entrepreneur bermakna pengusaha atau wirausahawan. Ada juga yang menyamakan istilah edupreneur dengan istilah teacherpreneur (Purnomo, 2017). Menjaga hubungan baik dengan wali siswa melalui melaksanakan janji dan pelayanan yang baik adalah bagian dari promosi wirausaha (Asitah, Usmawati, Rosyidah, \& Purnomo, 2017).

\section{Pemberdayaan Lingkungan}

Kelilingi diri Anda dengan "bisa melakukan", orang berpikiran maju. Jangan takut untuk mempekerjakan orang yang sangat cerdas, kreatif atau orang-orang dengan kepribadian atau gaya belajar yang berbeda dengan Anda. Pemikir yang berbeda sering melihat masalah / solusi dari perspektif yang berbeda, yang dapat sangat membantu (Driscoll, 2018).

\section{Kehendak Sang Pencipta}

Setiap manusia hamba Tuhan yang memiliki ilmu selayaknya harus mengamalkan ilmu tersebut (Asitah et al., 2017). Pendidikan adalah kunci untuk membuka pintu emas kesuksesan. Wirausaha pendidikan dengan motivasi bisnis dengan Allah Ta'ala sebagai bentuk kenyamanan untuk ibadah. Tips 
mengelola institusi pendidikan adalah niat mendidik dan berjuang karena Allah ta'ala. Niscaya rintangan sebesar apapun akan terasa ringan dihadapan kita. Melihat anak mengenal Allah Ta'ala dan sukses akhlak dan pengetahuannya merupakan kebahagiaan pendidik (Yuniarti et al., 2017). Prinsip pendidikan adalah sosial. Sebagai seorang guru, kita harus memiliki kepedulian sosial (Asitah et al., 2017). Guru harus bisa membangun generasi muda untuk masa depan. Hiduplah untuk mengamalkan ilmu (Sholichah et al., 2017). Hubungan pendidikan antara guru dan murid itu seperti aliran listrik dengan lampu. Bagaimana lampu itu bisa menyala kalau aliran listriknya juga mati ?. Bagaimana murid itu bisa berprestasi sedangkan guru sendiri tidak pernah berprestasi dan mendoakan (Fidiana et al., 2017). 


\section{References}

Asitah, N., Usmawati, D. Z., Rosyidah, E., \& Purnomo, A. (2017). MI Hasyim Asy'ari Ilmu Harus Terus Mengarus. In Wirausaha Pendidikan Indonesia (Jilid 2). Sidoarjo: UNUSIDA Press.

Bauer, D. (2019). 200 Tips for Effective School Leaders.

Retrieved June 18, 2019, from

https://www.betterleadersbetterschools.com/200-tipseffective-school-leaders/

Communicator. (2017). 4 Time Management Tips for Principals. National Association of Elementary School Principals, 40. Retrieved from https://www.naesp.org/communicator-june-2017/4time-management-tips-principals

Drewitt, P. (2017). 25 tips for School Principals. Retrieved June 18, 2019, from

https://www.linkedin.com/pulse/25-tips-schoolprincipals-paul-drewitt

Driscoll, M. (2018). 16 Success Tips for New 21st Century Principals. Retrieved June 20, 2019, from https://thinkstrategicforschools.com/16-success-tipsnew-21st-century-principals/

Edsys. (2016). 10 Awesome Tips to Manage School

Discipline Issues. Retrieved June 27, 2019, from https://www.edsys.in/10-awesome-tips-to-manageschool-discipline-issues/

Educational Leaders. (2019). Guides for managing your school. Retrieved June 20, 2019, from http://www.educationalleaders.govt.nz/Managingyour-school/Guides-for-managing-your-school

Fedena. (2018). Quality tips for better school management. Retrieved June 21, 2019, from https://fedena.com/blog/2018/11/quality-tips-forbetter-school-management.html 
Fidiana, W., Istiana, Z., Rosyidah, E., \& Purnomo, A. (2017). MINU Waru 2 Insan Berkilau Cahaya Manfaat. In Wirausaha Pendidikan Indonesia (Jilid 4). Sidoarjo: UNUSIDA Press.

Irawan, D. E., Purnomo, A., Sutiksno, D. U., Abraham, J., Alamsyah, A., Saputra, D. H., ... Rosyidah, E. (2018). Kajian Pendidikan Tinggi IDRI untuk DPR RI dan Ristek Dikti 2018. Bandung: ITB Press.

Iskandar, A., Rizal, M., Kurniasih, N., Sutiksno, D. U., \& Purnomo, A. (2018). The Effects of Multimedia Learning on Students Achievement in Terms of Cognitive Test Results. Journal of Physics: Conference Series, 1114(1), 012019. https://doi.org/10.1088/1742-6596/1114/1/012019

Kerns, K. (2016). 5 Time Management Tips for School Administrators. Retrieved June 21, 2019, from http://help.thesubservice.com/blog/5-timemanagement-tips-for-school-administrators Maula, I., Asitah, N., Munjidah, A., Nahdiyah, K., Yuniarti, D., Sholichah, S. A., ... Qori'ah, S. (2018). Kontribusi Kreativitas Guru SD dalam Induksi Pembelajaran. https://doi.org/http://doi.org/10.17605/OSF.IO/BS79 5

Maula, I., Mufidah, F. I., Rosyidah, E., \& Purnomo, A. (2017). SD Antawirya Islamic Javanese School Mother is Culture. In Wirausaha Pendidikan Indonesia (Jilid 1). Sidoarjo: UNUSIDA Press. Meador, D. (2019). 10 Things a Successful School Principal Does Differently. Retrieved June 21, 2019, from https://www.thoughtco.com/things-asuccessful-school-principal-does-differently-3194532 
Munjidah, A., Zannah, I. P. N., Purnomo, A., \& Rosyidah, E. (2017). MI Thoriqussalam Berpegang Kepada Rosul. In Wirausaha Pendidikan Indonesia (Jilid 4). Sidoarjo: UNUSIDA Press.

Nahdiyah, K., Amrina, S., Purnomo, A., \& Rosyidah, E. (2017). SD Taman Pendidikan Islam Porong Iman Kuat Bekal di Akhirat. In Wirausaha Pendidikan Indonesia (Jilid 2). Sidoarjo: UNUSIDA Press.

Peel District School Board. (2019). Becoming an Effective Youth Leader. Retrieved June 23, 2019, from http://www.peelschools.org/students/studentactivityc ouncil/tipsforbeingeffectiveschoolleader/Pages/defau lt.aspx

Purnomo, A. (2017). Pengertian Edupreneur. https://doi.org/10.31227/osf.io/8fnu6

Qori'ah, S., Sholichah, S. A., Purnomo, A., \& Rosyidah, E. (2017). Progresif Bumi Sholawat dengan Kebenaran Semua Pasti Ada Jalan. In Wirausaha Pendidikan Indonesia (Jilid 3). Sidoarjo: UNUSIDA Press.

Sholichah, S. A., Istiqomah, A., Rosyidah, E., \& Purnomo, A. (2017). MI Darun Najah Berfikir Berkarya Berdzikir. In Wirausaha Pendidikan Indonesia (Jilid 3). Sidoarjo: UNUSIDA Press.

Springer. (2019). Tips for Managing Organization.

Retrieved June 22, 2019, from https://www.springerld.org/springer-experience/center/parentprograms/tips-organization

Suci, S. H. A., Rosyidah, E., Asitah, N., Aini, N., Murni, A. W., Anam, F., ... Kuraesin, A. D. (2018). Learning from Picture and Picture Action Research : Enhancement of Counting Ability on Division of Numbers for Primary School Students. Journal of Physics: Conference Series, 1114(1), 012044. https://doi.org/10.1088/1742-6596/1114/1/012044 
Watanabe-Crockett, L. (2018). The 10 School Leadership Best Practices That Make a Difference. Retrieved June 21, 2019, from https://www.wabisabilearning.com/blog/10-schoolleadership-best-practices

Yuniarti, D., Kautsari, M. F., Sholichah, F., Purnomo, A., \& Rosyidah, E. (2017). SMP SMA Al-Amin Ponpes Bahrul Hidayah Serahkan pada Allah Ta'ala. In Wirausaha Pendidikan Indonesia (Jilid 1). Sidoarjo: UNUSIDA Press. 